\title{
Prácticas monumentales postexhumación: entre el pragmatismo y la escritura de la historia
}

\author{
Exhumazioen ondorengo monumentu-eraikuntza: pragmatismoaren \\ eta historiaren idazketaren artean \\ Post-Exhumation monumental practices: Between pragmatism \\ and writing of History
}

\author{
Daniel Palacios González \\ Universität zu Köln (Alemania) \\ daniel.palaciosgonzalez@uni-koeln.de \\ https://orcid.org/0000-0001-5620-0288
}

Recibido / Noiz jaso den: 24/11/2020

Aceptado / Noiz onartu den: 08/03/2021

\section{Resumen}

Desde el año 2000 se ha producido un nuevo proceso de exhumaciones de las fosas comunes de las personas asesinadas durante la Guerra y la Dictadura desde 1936. Sin embargo, hay una escasa visibilidad y reflexión en torno a la acción subsiguiente a las exhumaciones, que implica la reinhumación de los cuerpos. Este proceso tiene especial importancia dado que la mayor parte de los mismos no son identificados. En el presente artículo se aborda la acción de construir un monumento para alojar los cuerpos tras la exhumación. Se presentan resultados parciales de una investigación más amplia que combina técnicas histórico artísticas con etnográficas. Como conclusión se propone comprender estas acciones desde un punto de vista pragmático que a la vez puede ser interpretado como una voluntad de escritura de la historia por medio de la sepultura.

\section{Palabras clave}

Monumentos; memoria histórica; exhumaciones; giro forense; prácticas funerarias.

\section{Sumario}

1. INTRODUCCIÓN. 2. CUANDO LA EXHUMACIÓN NO ES SUFICIENTE. 3. SOlUCIONES "MONUMENTALES». 4. UNA ESCRITURA DE LA HISTORIA CORPORALIZADA. 5. CONCLUSIONES 6. BIBLIOGRAFía. 


\begin{abstract}
Laburpena. 2000. urteaz geroztik, prozesu berri bat dago martxan Gerra Zibilean eta Diktaduran 1936tik aurrera eraildakoen hobi komunak zabaltzeko. Ez da kasik gogoetarik egin, ordea, ezta jakitera eman ere, zer egiten den gorpuak hobitik atera ondoren: berriz ehortzi behar dira. Garrantzi handia du prozesu horrek, gorpu gehienak identifikatu gabe gelditzen baitira. Artikulu honetan, hilobitik atera ondotik gorpuak gordetzeko monumentu baten eraikuntza ikertzen da. Ikerketa zabalago baten emaitza partzialak aurkezten dira, zeinean teknika historikoak, artistikoak eta etnografikoak uztartu baitira. Azkenik, halako monumentuen eraikuntza ikuspegi pragmatikotik ulertzeko proposamena egiten da, erran nahi baita, ehorzketaren bidez historia idazteko borondate gisa.
\end{abstract}

Gako hitzak. Monumentuak; memoria historikoa; exhumazioak; auzitegien norabidea; hileta egiteko moduak.

\begin{abstract}
After the year, 2000 there was a new wave of mass grave exhumations. The graves keep buried the bodies of those people murdered during the War and Dictatorship since 1936. However, there is a limited visibility on those actions that followed exhumations, which includes re-inhumation of bodies. Those processes were essential since most of the bodies were not identified after their exhumation. This article deals with actions of building monuments to bury those exhumed bodies. It includes partial results wider research that combines art historical and ethnographical techniques. As a conclusion, it suggest understanding those actions as pragmatic decisions and at the same time as a will for writing history by means of burial actions.
\end{abstract}

Keywords. Monuments; historical memory; exhumations; forensic turn; funerary practicest.

\section{Introducción}

El año 2000 supone una piedra de toque en la historia en múltiples direcciones, la entrada en el nuevo milenio implicaría la explicitación artificial de un cambio de siǵlo que en realidad bien podría haberse producido hacia 1991 con el fin de la Unión Soviética como señala Eric Hobsbawm ${ }^{1}$. Para la cuestión que atañe a este texto habría dos sucesos que marcarían profundamente la política en el Reino de España y la relación de la sociedad con la memoria del pasado siǵlo xx y sus conflictos. En primer lugar, José Luis Rodríguez Zapatero presenta la «Nueva Vía» como corriente y plataforma electoral para el Partido Socialista Obrero Español (PSOE) en su XXXV Congreso del año 2000, que no resultaba sino una traducción al castellano de la «Thrid Way» del Partido Laborista Británico que bajo la tutela teórica de Anthony Giddens asumiría los principales propuestos neoliberales ${ }^{2}$. Esa decisión sería sintomática de la progresiva incorporación de paradigmas individualistas por parte de la sociedad en general y de los partidos de origen obrero en particular. Es precisamente Giddens quien, unido a Ulrich Beck

1 Hobsbawm, 1996.

2 Giddens, 2013. 
y Zyǵmunt Bauman, sienta las bases de la conformación de la teoría sociológica basada en el individualismo, considerando que existe un proceso de desmembramiento de los lazos sociales como parte de la globalización. Su «identity in high modernity» se basa en el «yo» ${ }^{3}$, Bauman lo asocia a la sociedad de consumo ${ }^{4}$, y Ulrich Beck y Elisabeth Beck-Gernsheim, a un individualismo vinculado a una segunda modernidad reflexiva ${ }^{5}$. No obstante, la apuesta de José Luis Rodríguez Zapatero por la teoría de Anthony Giddens al asumir presupuestos neoliberales y sociológicamente individualistas no es el único síntoma de la incorporación de ese tipo de paradiǵmas en el Reino de España, sino que también estará presente en un suceso que conecta esta situación preexistente con el motivo del artículo: la exhumación en ese mismo año 2000 de trece personas de una fosa común en Priaranza del Bierzo ${ }^{6}$.

La construcción del relato en torno a esta exhumación va a tener un componente individualista clave. Un nieto en busca de su abuelo que fue asesinado y enterrado en una fosa común durante la guerra de $1936^{7}$. Un suceso convertido en «mito», entendido desde la perspectiva barthesiana ${ }^{8}$, tanto desde los medios de comunicación como desde la literatura académica de las últimas dos décadas. Desde entonces se ha hablado de la vuelta de los «fantasmas de la Guerra Civil» ${ }^{9}$, de una «sacudida de los cimientos de la sociedad $»^{10}$, incluso del «resurgir del pasado» ${ }^{11}$. Así, como «mito», habría inspirado presumiblemente a otros familiares a buscar y promover exhumaciones tras realizar una introspección en su memoria familiar, para apropiarse del cuerpo del asesinado como acto de justicia o restitución, pese al nulo impacto en relación a las sentencias y los victimarios de las apelaciones a la ONU por la ARMH o la denominada Querella Argentina ${ }^{12}$, y de la inoperancia en materia jurídica del Estado español ${ }^{13}$. Pero más allá de los debates abiertos al respecto sobre la dimensión familiar, jurídica y política del

3 Giddens, 1991.

4 Bauman, 2018.

5 Beck y Beck-Gernsheim, 2001.

6 Etxeberria Gabilondo et al., 2002.

7 Asociación para la Recuperación de la Memoria Histórica, 2000.

8 El mito es definido por Roland Barthes como una acción comunicativa por la cual al signo concreto, que basa su existencia en un sistema semiológico de primer orden, se le sustituye el sentido original basado en la percepción humana por otro basado en un sistema semiológico de seǵundo orden de manera que se aprovecha la confianza depositada por el lector en el siǵnificado del siǵno origínal para intentar persuadirnos de algo que no es objetivamente verdadero. Ver Barthes, 2014.

9 Ferrándiz, 2006, pp. 7-12.

${ }_{10}$ Yusta Rodrigo, 2014.

11 Aguilar Fernández y A. Payne, 2018

12 Montoto Ugarte, 2017, p. 2.

${ }_{13}$ Peinado, 2020. 
proceso de exhumaciones, merece la pena prestar atención a un punto velado por la narrativa individualista del nieto en busca de su abuelo. Se trata de un punto clave en todo este relato y que resulta fundamental en términos tanto prácticos como simbólicos: el destino final de los cuerpos exhumados.

Las omisiones, aunque evidentes, son las que hacen los «mitos» más verosímiles y el espectador entra en el juego de ignorar esas inverosimilitudes para participar plenamente de la ficción. El relato generado en torno a las exhumaciones y la denominada «memoria histórica» no escapa a ese patrón. Contra el relato de los cuerpos ubicados en «cunetas» popularizado desde el inicio por los periodistas y recientemente llevado al cine ${ }^{14}$, revisar los mapas de fosas realizados durante los últimos años por entidades autonómicas y universitarias arroja una verdad incontestable: más de seiscientas fosas no solamente están localizadas, sino que además en un alto porcentaje han sido exhumadas y disponen de un monumento sobre la fosa o tras la exhumación de la misma. Es el monumento el testimonio que de ellas nos queda, más allá de los rastros documentales en archivo, con los cuerpos de los exhumados. No obstante, la mayor parte de la literatura académica en el campo no ha tratado este destino final de los cuerpos sino otras cuestiones referidas al propio impacto social y político, destacando los trabajos de Francisco Ferrándiz ${ }^{15}$, Layla Renshaw ${ }^{16}$ y Walther L. Bernecker ${ }^{17}$, entre otros ${ }^{18}$. Puntualmente, el destino final de los cuerpos sí que ha sido trabajado con detalle por Javier Giráldez, cuya tesis trabaja con sistematicidad y amplitud esta realidad en el contexto de Andalucía ${ }^{19}$, Conxita Mir en las capitales catalanas ${ }^{20}$, Jesús Alonso en Euskadi ${ }^{21}$, Jesús Aguirre en La Rioja ${ }^{22}$, John Thompson en Galicia ${ }^{23}$, Francisco Ferrándiz en la experiencia particular de Aranda de Duero ${ }^{24}$ y Vicent Gabarda en Paterna ${ }^{25}$. A ellos se puede sumar el reciente trabajo de Layla Renshaw quien atiende al debate de la ética de las conmemoraciones, incluyendo breves reflexiones sobre los enterramientos colectivos tras la exhumación ${ }^{26}$. Así, la limitación de literatura al respecto y que contrasta con la abundancia de textos dedicados

\footnotetext{
${ }^{14}$ Joric, 2018, pp. 10-11.

15 Ferrándiz, 2014.

16 Renshaw, 2016.

17 Bernecker y Brinkmann, 2020.

18 Puede encontrarse una bibliografía exhaustiva del tema en Alonso et al., 2020.

19 Giráldez Díaz, 2014.

${ }^{20}$ Mir y Gelonch, 2013.

21 Alonso Carballés, 2017.

22 Aguirre González, 2012.

23 Thompson, 2014.

24 Ferrándiz, 2018.

${ }^{25}$ Gabarda Cebellán, 2019.

26 Renshaw, 2019.
} 
a las exhumaciones en sí mismas se presenta como un campo sobre el que trabajar en el futuro, pues el destino final de los cuerpos debería resultar una parte fundamental del análisis dado que presumiblemente era uno de los objetivos de la acción de exhumar, especialmente en un contexto en el que estas acciones no han tenido vinculaciones judiciales.

Por tanto, con el presente texto propongo abordar de una manera breve la práctica monumental en relación a la exhumación de las fosas comunes de los asesinados en la guerra y la dictadura desde 1936. Planteo cómo esta práctica puede ser interpretada a priori como una solución praǵmática al destino final de los cuerpos frente a las limitaciones a la hora de identificar los cuerpos, un argumento que rebato, puesto que a la hora de desarrollar la práctica monumental misma comienza a entrar en juego una forma de escritura de la historia sobre el propio territorio a través de los cuerpos y del monumento en el que se imbrican. Para sostener tales argumentos urge explicitar que forman parte de las conclusiones de una investigación mucho más amplia que se viene desarrollando desde 2018 como parte de un proyecto de investigación doctoral MSCA-H2020COFUND, en el marco del programa EUmanities, en la a.r.t.e.s. Graduate School for the Humanities Cologne de la Universidad de Colonia ${ }^{27}$ y el proyecto de investigáción del CSIC dirigido por Dr. Francisco Ferrándiz «SUBTIERRO: Exhumaciones de fosas comunes y derechos humanos en perspectiva histórica, transnacional y comparada ${ }^{28}$. Gracias a dicho marco institucional he podido desarrollar mi propia propuesta de investigación interdisciplinar sin las limitaciones y corsés académicos a los que las disciplinas humanísticas y sociales están acostumbradas. Al tratarse de artefactos que han sido vagamente documentados, en breves notas de prensa, donde lo importante no era el monumento sino la exhumación, o en contratos y documentos administrativos que no suelen ser más que partidas presupuestarias o adjudicaciones, desde la historia del arte basada en la revisión documental y de la propia obra, resulta imposible aportar nada al respecto. De este modo, se apostó por el uso de técnicas etnoǵráficas a fin de suplir esas limitaciones y poder entender estos artefactos como consecuencia de una práctica y no como un objeto estático en sí mismo. De igual manera se han visitado una muestra de 100 municipios de los más de 600 de los que dispongo en mi base de datos, y se han realizado entrevistas a los promotores de las iniciativas, así como

${ }^{27}$ a.r.t.e.s. EUmanities ha recibido fondos del programa de la Unión Europea de investigación e innovación Horizonte 2020 bajo el Marie Skłodowska-Curie grant aǵreement No 713600. Proposal: 713600 - artes EUmanities. Más información disponible en CORDIS: http://cordis.europa.eu/ project/ren/203182_de.html [consultado el 02/03/2021].

28 SUBTIERRO: Exhumaciones de fosas comunes y derechos humanos en perspectiva histórica transnacional y comparada. Proyecto I+D+i CSO2015-66104-R. Más información disponible en: https://politicasdelamemoria.orǵ/ [consultado el 02/03/2021]. 
a otros agentes implicados en las mismas de cara a poder elaborar un análisis cualitativo del proceso sin dejar de prestar atención a que lo que nos encontramos son patrones al interior de una dinámica muy heterogénea y que en ningún caso debe ser generalizada o sujeta a normas fijas ${ }^{29}$. Mi apuesta metodológica, por tanto, no innova realmente sobre la disciplina. Trato de dotarla de nuevo de uno de sus múltiples sentidos originales, al atender las formas marǵinalizadas no por la sociedad como tal, sino por la propia historia del arte contemporáneo. Trato de no entender de una manera estanca la producción de cultura visual, y a su vez cubrir un ángulo muerto en la producción de literatura académica sobre las exhumaciones. Hagoo así explícito frente al paradiǵma científico que el monumento que integra los cuerpos exhumados en su interior goza de un carácter de signo lingüuístico en sociedad que lo convierte inevitablemente en un campo en $\operatorname{disputa}^{30}$.

\section{Cuando la exhumación no es suficiente}

En los últimos años los procesos de exhumación desarrollados durante la Transición han comenzado a ser estudiados desde los ámbitos académico e institucional. En este sentido, diversos autores han arrojado luz sobre un proceso en el que las referencias más abundantes no eran sino la cobertura de las exhumaciones en tanto que sucesos por Interviú ${ }^{31}$. Un proceso de exhumaciones llevado a cabo principalmente por familiares y allegados, con participación de militantes y eventualmente de corporaciones municipales. De ese proceso, Jimi Jiménez, en su estudio del proceso de exhumaciones de la Transición, ha considerado que habría una serie de características comunes tales como el papel preponderante de anónimos y familiares orǵanizados en comisiones gestoras o a través de asambleas, con vistas a una autogestión comunitaria del proceso. Proceso del cual deberían hacer frente a los gastos y en muchas ocasiones a la exhumación misma de los cuerpos con sus propias manos ${ }^{32}$. Por otra parte, se ha considerado en perspectiva comparada en el territorio que ese tipo de comisiones gestoras permitieron por la presión colectiva afrontar las trabas administrativas y romper con la lógica del miedo impuesta hasta entonces a la hora de organizar un homenaje colectivo y público ${ }^{33}$. Finalmente, para caracterizar el proceso, Zoé de Kerangat

\footnotetext{
${ }^{29}$ Bod, 2013.

${ }^{30}$ Voloshinov, 2014.

${ }^{31}$ Aguilar y Ferrándiz, 2016.

${ }^{32}$ Gastón Aguas y Layana Ilundain, 2019.

${ }^{33}$ Aguilar, 2018.
} 
plantea cómo la concentración de exhumaciones en Navarra y la Rioja, a la que se suman experiencias más puntuales en Extremadura, Andalucía o Murcia, hablaría de la importancia de la propagación de la idea de la posibilidad de exhumación a través de redes informales de contacto entre vecinos, lo que ella define en tanto que expansión como «ondas» ${ }^{34}$. Pero evitando de nuevo el relato mítico, como el de Priaranza, urǵe prestar atención al destino final de los cuerpos en estos procesos de exhumación, pues la exhumación misma no era el fin sino un medio, lo cual ha quedado en ocasiones velado.

Una de las contribuciones más exhaustivas al respecto ha sido el trabajo dedicado por Jesús Aguirre a la represión en La Rioja, un proceso que estudia municipio por municipio y del cual recupera no solamente los antecedentes políticos, sociales y económicos previos a la represión sino también la recuperación de los cuerpos que se desarrolló en los años setenta en el marco de los procesos de exhumación, recogiendo también el destino final de los cuerpos. Así, en su investigación recoge gran cantidad de material fotográfico del que se denotan dos factores fundamentales que también definirían el proceso: la ausencia de una metodología forense, por lo cual los cuerpos eran exhumados colectivamente, y la reinhumación colectiva de los cuerpos en grandes panteones ${ }^{35}$. Pese a que la exhumación colectiva puede considerarse como una «limitación» o «imposibilidad», a la vista de las tendencias actuales ${ }^{36}$ e históricas de realizar exhumaciones con metodologías científicas ${ }^{37}$, quizás el paradiǵma colectivo y la importancia del destino simbólico final de los cuerpos pudo estar por encima de tales nociones y ser nosotros quienes desde la actualidad las estemos proyectando. Uno de los pioneros de las exhumaciones de los años setenta fue José Vidorreta, quien junto a otros compañeros orǵanizó ya en 1976 una comisión para organizar un homenaje que tuvo lugar al año siguiente sobre la propia fosa común donde se encontraban los cuerpos de los asesinados en Cervera del Río Alhama. No obstante, José Vidorreta perseveró y procedió en 1978 a la exhumación de la fosa, para finalmente dar sepultura a los cuerpos en el cementerio de su localidad ${ }^{38}$. «No pudimos antes. Yo tenía una inquietud de enterrar aquí los restos, y los trajimos: el día que los fusilaron, pero a los 41 años. Yo digo que aquel día fue el día más grande de mi vida. Nunca he tenido una emoción tan ǵrande como aquel día» ${ }^{39}$. Ese «aquí»se convirtió en un lugar fundamental para entender la historia de Cervera del Río Alhama. Se trata hoy de un panteón monumental que se destaca en el cementerio,

\footnotetext{
${ }^{34}$ De Kerangat, 2019.

35 Aguirre González, 2012.

${ }^{36}$ Etxeberria Gabilondo y Solé i Barjau, 2019.

${ }^{37}$ Saqqa Carazo, 2020.

${ }^{38}$ De Kerangat, 2019.

${ }^{39}$ Entrevista a José Vidorreta en Cervera del Río Alhama, 21 de enero de 2019.
} 
donde la inicial sepultura se fue ampliando, con más placas, con los nombres, con epitafios que significaban políticamente a los cuerpos y el acto de su asesinato, y, sobre todo, un lugar donde cada año se organizan homenajes.

Aparentemente en la actualidad la situación ha cambiado, con la incorporación de técnicos en la búsqueda de los cuerpos como parte del proceso que se ha definido en tanto que "giro forense ${ }^{40}$ de manera que el saber de la comunidad se habría sustituido por el biomédico de los «especialistas» siguiendo la tesis de David Le Breton ${ }^{41}$. Este sostiene por qué el cuerpo de la modernidad sería el resultado de un retroceso de las tradiciones populares y de la llegada del individualismo occidental que marca la frontera entre un individuo y otro, el repliegue del sujeto sobre sí mismo ${ }^{42}$. Así, desde el año 2000 se han exhumado con la participación generalmente de algún tipo de personal científico, aunque no siempre, más de 700 fosas, según las últimas cifras ${ }^{43}$. Pero a nivel social resulta fundamental comprender que se ha generado una imagen heroica en torno a la figura del forense y las posibilidades de los análisis óseos en lo que respecta a la identificación de los cuerpos. Una confianza ciega de la sociedad que no puede ser consciente de las limitaciones de la técnica dada la irresponsable acción de periodistas y cineastas, como sucede con el film El Silencio de otros $(2018)^{44}$, y, sobre todo, de la popularización de series televisivas, en lo que se ha denominado el «efecto CSI» ${ }^{45}$. La posibilidad de «poseer» el cuerpo del familiar asesinado enlazaría precisamente con el planteamiento de Le Breton sobre el individualismo aplicado al tratamiento de los cuerpos, pues como afirma «las sociedades occidentales hicieron del cuerpo una posesión más que una cepa de identidad» ${ }^{46}$. No obstante, la realidad dista de la ficción donde la metodología científica ofrece respuestas absolutas y happy endings, ya que miles de esos cuerpos exhumados en los últimos veinte años no han sido identificados.

Los datos más recientes sugeridos por Fernando Serrulla y Francisco Etxeberria plantean que, existiendo un total de 2457 fosas, hacia 2020 se habrían exhumado más de 700. De ellas se habrían recuperado los cuerpos de más de 8000 individuos, y se calcula que aún quedarían 20000 individuos sin exhumar. No obstante, reconocen que menos de un tercio podrían ser identificados. Tomando como referencia la cifra de 130099 asesinados, los forenses señalan que solo han sido identificados

\footnotetext{
${ }^{40}$ Anstett y Dreyfus, 2015.

${ }^{41}$ Le Breton, 2012, p. 83.

${ }^{42}$ Le Breton, 2012, p. 23.

${ }^{43}$ Etxeberria Gabilondo y Solé i Barjau, 2019.

${ }^{44}$ Martín Maestro, 2019.

45 Schweitzer y Saks, 2007.

${ }^{46}$ Le Breton, 2012, p. 23.
} 
genéticamente el 0,2\%, lo que implicaría una cifra de 260 individuos ${ }^{47}$. En este mismo sentido, en su tesis de 2014, Javier Giráldez señala en su informe las dificultades en torno a la identificación de los asesinados en Andalucía, dadas las escasas identificaciones tras la exhumación de 60 fosas desde el año 2000. Las limitaciones técnicas y la ausencia de parientes en vida resultan condicionantes que impiden en ocasiones identificar a los exhumados, pero incluso sin limitaciones técnicas y existiendo familiares en vida en ocasiones no es posible la identificación. Giráldez lo ejemplifica a través de la exhumación de una fosa en Gerena, donde no fue posible identificar a todas las mujeres exhumadas pese a que tenían familiares vivos: «en definitiva, es muy complicado devolver las víctimas a sus familiares. Es conveniente, por responsabilidad y por sentido común, hacer ver esto a los familiares antes de comenzar cualquier proceso exhumatorio» ${ }^{48}$. Como comentaba anteriormente, las expectativas generadas desde los medios de comunicación han aǵravado la situación, ya que de las altas expectativas puestas en la posibilidad de exhumar y recuperar de manera individualizada el cuerpo de un pariente asesinado por parte de un familiar en vida se llega en la mayor parte de las ocasiones a una nueva pérdida de la identidad del cuerpo entre los otros asesinados. A esa situación se han enfrentado familiares y colectivos en diversos puntos del territorio, sin embargo, frente a la indeseable situación de carecer de una identificación individual surge la necesidad y la posibilidad de afrontar de manera positiva el momento posterior a la exhumación: la práctica monumental post-exhumación.

\section{Soluciones «monumentales»}

Gracias al trabajo de Vicent Gabarda Cebellán conocemos la dimensión de uno de los conjuntos de fosas comunes más grandes de todo el territorio, las ubicadas en Paterna, localidad de la periferia de Valencia donde fueron ejecutadas más de 2000 personas tras la llegada de los sublevados a la que fue capital temporal de la República Española ${ }^{49}$. A través de su trabajo también conocemos de manera sistemática la acción que se desarrolló durante décadas sobre las fosas, lugares donde los familiares tenían en muchas ocasiones un conocimiento casi exacto de la ubicación del cuerpo de su familiar por haberse tratado de una represión organizada y sistemática que derivó en la construcción de grandes fosas de pozo en las que iban enterrándose los asesinados según las jornadas de ejecución. Sobre ellas las familias y otros colectivos comenzaron a llevar flores, a ubicar

\footnotetext{
${ }^{47}$ Alonso et al., 2020.

${ }^{48}$ Giráldez Díaz, 2014, p. 292.

${ }^{49}$ Gabarda Cebellán, 1986.
} 
cerámicas con sus nombres, a construir recintos sobre las mismas en piedra y a ubicar lápidas con sus fotografías y epitafios. A ello se sumó la construcción de diversos monumentos en el entorno ${ }^{50}$, y a ello se suma que esas fosas son el lugar de homenajes anuales, algunos de los más grandes de todo el Estado ${ }^{51}$, como el de la «Caravana Republicana de Valencia». Y finalmente desde 2017 se han producido trabajos de exhumación sobre esas fosas ${ }^{52}$. Esto ha derivado en una situación compleja: la exhumación implicaba la destrucción de la estructura monumental construida sobre la fosa para poder acceder a los cuerpos y la exhumación ha implicado también que muchos de los cuerpos exhumados no estén siendo identificados o no vayan a tener un familiar que los reclame. Ante dicha situación, las diversas asociaciones organizadas en torno a cada fosa han comenzado a coordinarse ${ }^{53}$. De este encuentro se han planteado, entre otros, un objetivo: el de la construcción de un panteón o columbario monumental donde los cuerpos de aquellos que no fuesen identificados o reclamados pudiesen alojarse, ya libres del destino al que físicamente se les condenó enterrados en las fosas y simbólicamente reconocidos a través del monumento. Una acción a la que, sin embargó, el Ayuntamiento de Paterna, reǵido por el PSOE, se nieǵa. El Ayuntamiento solo ofrece a los familiares enterrarlos de nuevo en las fosas comunes, para su profunda disconformidad ante la reproducción del mismo orden «necropolítico» ${ }^{54}$ que instauró la dictadura.

La problemática ante la posibilidad de la recuperación individual de los cuerpos devuelve a las fosas comunes su carácter colectivo, un carácter que ha quedado explicitado precisamente en las soluciones formales a la hora de reinhumar los cuerpos tras las exhumaciones desde los primeros años 2000. En Villamayor de los Montes, donde los trabajos de exhumación concluyeron en 2004 con la intervención de la Sociedad de Ciencias Aranzadi y la Universidad Autónoma de Madrid en una iniciativa promovida a través de la Asociación para la Recuperación de la Memoria Histórica de Burgos ${ }^{55}$, se recuperaron 46 cuerpos, de los que solo 9 fueron identificados ${ }^{56}$, de manera que la decisión por parte del colectivo promotor fue la de la reinhumación de los cuerpos en un panteón colectivo en el cementerio del municipio. Una situación que comenzó a ser recurrente y que llevaría a esa misma asociación, tras promover numerosas exhumaciones en la región, a construir en el cementerio de Aranda de Duero un gran complejo mo-

\footnotetext{
${ }^{50}$ Gabarda Cebellán, 2019, pp. 176-180.

51 Martínez, 2019.

52 Iǵlesias, 2017.

53 20minutos, 2019.

${ }^{54}$ Mbembe, 2019.

55 Ferrándiz, 2013.

${ }^{56}$ Fuentes, 2005.
} 
numental que permitiera la reinhumación ordenada de los cuerpos individualizados recuperados de las fosas comunes y no identificados o no reclamados. Una estructura que además de tener un carácter funcional imprime sobre los cuerpos que contiene una lectura ideológica: se los considera «semillas de la libertad», así como «víctimas del fascismo», además, sus nombres se acompañan de banderas republicanas y numerosas ofrendas florales se encuentran a los pies del monumento. La solución parte de la necesidad de la asociación promotora de las exhumaciones de dar una solución práctica, de su sensibilidad política a la hora de ejecutarla para dotar a los cuerpos de un reconocimiento simbólico y, adicionalmente, del apoyo material del ayuntamiento local, quien, pese a no estar forzado a ello, apoyó la iniciativa. Y es este último punto una cuestión fundamental: tras la ausencia de un marco regulatorio desde el inicio de estas exhumaciones en el año 2000, el marco instaurado en el 2007 con la Ley 52/2007, de 26 de diciembre, por la que se reconocen y amplían derechos y se establecen medidas a favor de quienes padecieron persecución o violencia durante la guerra civil y la dictadura no solo no resuelve, sino que complejiza la situación. A la hora de abordar las exhumaciones que se realicen al amparo de la Ley de 2007, simplemente aclara a cerca del destino de los cuerpos:

Se inhuman en el cementerio de la población donde se halla la fosa. Para ello, se utilizarán los contenedores más adecuados, según las indicaciones de técnicos en conservación y restauración. Cada individuo será inhumado de manera individualizada previa una identificación que permita su localización en futuras exhumaciones, junto con los efectos personales que hayan sido hallados. Dicha identificación deberá incluir en todos los casos el número de registro de estudio ${ }^{57}$.

Una recomendación sin consecuencias penales en el caso de ser incumplida, que ha implicado que numerosos cuerpos hayan vuelto a ser enterrados bien en su fosa común de origen o bien en la fosa común colectiva del cementerio o en el osario, como ocurrió tras la exhumación de tres mujeres en el Valle del Tietar ${ }^{58}$, o que los cuerpos desaparezcan de la fosa y tampoco se entierren en el propio municipio, para pasar de la fosa a cajas de plástico que permanecerán durante años en oficinas como las de la ARMH en Ponferrada, como ha sucedido con los cuerpos no reclamados o no identificados exhumados en Guadalajara en 2016 ${ }^{59}$. Ante

${ }^{57}$ Cortes Generales, «Ley 52/2007, de 26 de diciembre, por la que se reconocen y amplían derechos y se establecen medidas en favor de quienes padecieron persecución o violencia durante la guerra civil y la dictadura», Boletín Oficial del Estado. Identificador: BOE-A-2007-22296, publicado el 27 de diciembre de 2007.

${ }^{58}$ Martín Chiappe, 2020.

59 elDiario.es, 2016. 
dicha situación, producto de un pobre marco regulatorio que deja los cuerpos en manos de autoridades y organizaciones que pueden tener una escasa sensibilidad política o, por el contrario, una voluntad política contraria al proceso, desde la iniciativa local y autonómica se han dado diversas soluciones.

Ya en 2009 en Cataluña se hizo frente también de manera pionera a la situación derivada de la apertura de fosas de cuerpos en el entorno de la Batalla del Ebro; cuerpos que, de nuevo, fue imposible identificar ${ }^{60}$, y para lo que se construyó un gran memorial que explica la batalla y aloja los cuerpos con los nombres de quienes se encuentran desaparecidos desde aquel combate, se encuentren allí o no ${ }^{61}$. En 2017 tiene lugar otra de las acciones referentes en este contexto, la dirigida por el Gobierno Vasco, desde el Instituto de la Memoria, la Convivencia y los Derechos Humanos, Gogora, al promover el denominado «Columbario de la Dignidad» en Elgoibar. Una gran estructura monumental que ha permitido no solamente alojar los cuerpos sino tener un espacio de memoria oficial que dota de significado político a las personas asesinadas y cuyos cuerpos han sido exhumados, con el reconocimiento institucional que implica que la iniciativa sea del Gobierno autonómico. El lehendakari Iñigo Urkullu lo describiría en su inauguración en 2017 como sigue: «Este espacio simboliza el paso del olvido a la memoria, de la oscuridad a la luz [...], un paso más en la recuperación de la memoria histórica» ${ }^{62}$. También en 2015, producto de un convenio entre el Gobierno de Navarra y el Ayuntamiento de Pamplona, se creó un panteón en el Cementerio de Pamplona para albergar los cuerpos exhumados y no identificados en Navarra. Allí sucesivamente se han reinhumado cuerpos desde entonces haciendo frente a una necesidad indirecta del Plan de Exhumaciones del Gobierno de Navarra ${ }^{63}$.

Finalmente, urge mencionar una iniciativa aún por inaugurar, pero cercana a su conclusión, que es la del Parque de la Memoria en construcción sobre el antiguo cementerio de San Rafael en Málaǵa. Allí se habrían llegado a producir más de 4000 asesinatos, donde el expresidente del Gobierno Carlos Arias Navarro desempeñó como fiscal ${ }^{64}$. El desmantelamiento del cementerio por parte del ayuntamiento forzó a que se interviniesen las fosas por iniciativa de la Asociación contra el Silencio y el Olvido por la Recuperación de la Memoria Histórica de Málaga ${ }^{65}$. Los trabajos, coordinados por la asociación con apoyo del Ayuntamiento, la Diputación y la Junta, finalmente derivaron en la reinhumación de la totalidad de los cuerpos en una gran pirámide de mármol, con los nombres de los

\footnotetext{
${ }^{60}$ Ramos, 2017.

${ }^{61}$ COMEBE.

${ }^{62}$ Gogora, 2017.

63 EITB, 2019.

${ }^{64}$ Thomas, 2003.

${ }^{65}$ Fernández, 2010.
} 
asesinados. El día que se inaugure será el complejo monumental más ǵrande en todo el territorio vinculado a una fosa común. Hoy, a finales de 2020 , mientras se presenta el anteproyecto de Ley de Memoria Democrática, que ha generado profundo malestar entre la mayor parte de organizaciones de memoria debido a que refuerza el régimen de impunidad al no declarar la ilegalidad de las condenas y al reconocer la legalidad de la dictadura y por de nuevo ignorar la problemática del destino final de los euerpos ${ }^{66}$, se producen también los trabajos de exhumación en una de las más grandes fosas comunes de Andalucía: la de Pico Reja, en Sevilla ${ }^{67}$. María Luisa Hernández, nieta de uno de los allí asesinados, es consciente de las dificultades del proceso, de lo poco probable de que entre los miles de asesinados sea factible la identificación del cuerpo de su abuelo. Por ello, me explicaba así sus deseos:

Tenemos un referente que es muy bonito, lo que están haciendo en el parque de la memoria en lo que es el Cementerio de San Rafael de Málaga. Un parque precioso, donde se va a poder estar sentado en silencio, donde van a procurar que allí no haya juegos, de respeto y demás. Aquí en Pico Reja igualmente se podría hacer un monumento bonito, allí han hecho una pirámide con los nombres, aquí pues algo que se ocurra estéticamente hermoso, y también majestuoso, que tenga, un porte bonito y que tuviera también los nombres de estas personas asesinadas ${ }^{68}$.

En este punto resulta sugerente la reflexión de David Le Breton: «La medicina se aleja, entonces, de un recurso, el de lo simbólico, que, sin embargo, podría potenciar sus efectos ${ }^{69}$. Por tanto, pese a las limitaciones en términos de recuperación e identificación individualizada de los cuerpos, el «giiro forense» podría potenciar los efectos de lo simbólico tal y como plantea Le Breton. Con ello contribuiría a un particular ejercicio de escritura de la historia, que se va a describir brevemente a continuación.

\section{Una escritura de la historia corporalizada}

En el cementerio de Castellón desde 2019 se desarrollan trabajos de exhumación de las fosas comunes donde fueron enterrados aquellos que fueron asesinados por el Estado español hasta $1944^{70}$. La iniciativa, coordinada por el Grup

\footnotetext{
${ }^{66}$ Peinado, 2020.

${ }^{67}$ Ruiz, nombres.org.

${ }^{68}$ Entrevista a María Luisa Hernández, 27 de julio de 2020.

${ }^{69}$ Le Breton, 2012, p. 184.

${ }^{70}$ Ródenas, 2016.
} 
per la Recerca de la Memòria Històrica de Castelló, atiende a las voluntades de familiares particulares, y cuenta con apoyo del Ayuntamiento y la Diputación ${ }^{71}$. A aquel lugar, ya desde tiempos de la propia posguerra, algunos familiares habían acudido a llevar flores ${ }^{72}$, otros no han sido conscientes hasta fechas recientes de que los cuerpos de sus familiares se encontraban en aquel lugar. Durante una conversación con algunos de los familiares implicados en el proceso, la nieta de uno de los asesinados me explicó que pese a que apoyaba el proceso de exhumación había decidido no llevarse el cuerpo de su abuelo en el caso de que fuese identificado, ya que el Grup per la Recerca de la Memòria Històrica de Castelló estaba buscando el apoyo del Ayuntamiento y la Diputación para construir un panteón monumental donde conservar los cuerpos que no fuesen reclamados o identificados. Me explicó como su decisión cuando ella falleciese iba a ser que la incinerasen, y el panteón familiar podría desaparecer en el osario dado que no habría quien pagase las tasas dadas las políticas especulativas de ayuntamientos e iǵlesias en un futuro. Por ello prefería que el cuerpo de su abuelo exhumado quedase en el proyecto de monumento en el cementerio de Castellón, pues de esa manera «estaría allí para siempre».

La iniciativa del Grup per la Recerca de la Memòria Històrica de Castelló converge con todas las iniciativas citadas y no citadas, que tienen como una de sus finalidades la conservación de los cuerpos exhumados de una fosa común: desde los panteones que responden a fosas concretas, como el citado de Villamayor de los Montes, a los proyectos institucionales producto de un plan premeditado de intervención sobre las fosas inserto en un programa más amplio que incluya educación y difusión como el de Elgoibar o Pamplona. El punto de interés de estas iniciativas es que, como mencionaba con anterioridad, no solamente plantean dar un destino final a los cuerpos por el cual se dote de un "contenedor adecuado» como indicaba la Ley de 2007. Se están introduciendo los cuerpos en complejos arquitectónicos que responden a diversos criterios formales pero que tienen en común un carácter de "gesto» en relación a los cuerpos. En este sentido resulta relevante recuperar la concepción de Paul Ricoeur a cerca de las sepulturas. Más allá de la función praǵmática de ubicar los muertos en el exterior de la ciudad por criterios sanitarios, enterrándolos o ubicándolos en estructuras que los alberguen, existe una gestualidad que no es momentánea, que no se limita al entierro y que, por el contrario, «la sepultura permanece, porque permanece el gesto de enterrar; su recorrido es el mismo del duelo que transforma en presencia interior la ausencia física del objeto perdido. La sepultura como lugar material se convier-

\footnotetext{
${ }^{71}$ Suárez, 2019.

72 Ródenas, 2016.
} 
te así en la señal duradera del duelo, el memorándum del gesto de sepultura» ${ }^{73}$. Por tanto, resulta fundamental prestar atención al valor simbólico de ese «gesto de sepultar». Un gesto que va más allá del paradiǵma individualista que ha guiado las exhumaciones y del paradigma promovido por los medios con los sucesos de Priaranza del Bierzo.

Existe una voluntad de trascendencia vinculada a las que denomino «prácticas monumentales postexhumación» que pasa por la integración de los cuerpos en el monumento que los sepulta y que los fija al territorio. En este sentido resulta reveladora la ecuación que Ricoeur establece entre escritura de la historia y gesto de la sepultura a través de la teoría de Michel de Certeau. Estos plantean como la propia escritura de la historia se asemeja a la acción del enterramiento: el exorcismo de la muerte se introduce en el discurso a través de la función simbólica, dotando al pasado de un lugar en el lenguaje y de un espacio propio que lo «marca». «La escritura es una sepultura en el doble sentido del término, en tanto que en el mismo texto tanta honra como da fin» ${ }^{74}$.

Esa acción no solo dotaría de un espacio a los muertos, sino también redistribuiría el espacio de posibilidades para los vivos usando la narrativa de los muertos como un medio de fijar un lugar para los vivos a través de una práctica monumental tras la exhumación. De Certeau atribuye una función simbolizadora a ese «gesto de sepultura» que, además, "permite a la sociedad situarse dotándose de un pasado a través del lenguaje y así abrirse un espacio a sí misma en el presente» ${ }^{75}$. Por tanto, si asumimos el «gesto de sepultura», como suǵiere Ricoeur, y le imprimimos los atributos de Certeau sobre la escritura de la historia como rito de enterramiento, las prácticas monumentales sobre fosas comunes pueden ser leídas como un «gesto significativo» ${ }^{76}$ más que como un simple artefacto. Y ese carácter de "gesto signnificativo» es del que se traduce que sea un campo en disputa siguiendo la teoría de Valentin Voloshinov. El «signno» resultante de ese «gesto» no «reflejaría» sino que «refractaría» por su carácter ideológico. Se convierte en la intersección de intereses sociales de orientación muy diversa, aun dentro de los límites de un mismo colectivo semiótico ${ }^{77}$. Ello puede percibirse en la tendencia hegemónica a entender el proceso de las exhumaciones como un cierre de ciclo materializado en la recurrente expresión utilizada por $\operatorname{los} \operatorname{medios}^{78}$, académicos ${ }^{79}$ o dirigentes polí-

\footnotetext{
${ }^{73}$ Ricoeur, 2010, p. 480.

${ }^{74}$ De Certeau, 1988, p. 101

${ }^{75}$ De Certeau, 1988, p. 100.

76 Voloshinov, 2014, p. 32.

77 Voloshinov, 2014, p. 47.

78 RTVE, 2019.

${ }^{79}$ Fouce Fernández, 2008.
} 
ticos ${ }^{80}$ para hablar de la apertura de las fosas como un acto para «cerrar heridas», algo que viene de la mano de una construcción social de la imaǵen del asesinado en tanto que «víctima» ${ }^{81}$. Y cómo, por el contrario, a la hora de construir estructuras para sepultar los cuerpos exhumados se iría más allá de la noción del entierro «digno» en el ámbito privado en favor de la trascendencia social e histórica desde la idea del «honor» a través de la nueva imagen que ofrecen los cuerpos mismos de los asesinados integrados en una nueva estructura.

Desde esa idea, por tanto, del «gesto de sepultura», sería a través de la cual se escribe la historia con los cuerpos de los exhumados, y este sería un proceso de producción de «signos». Proceso al respecto del cual Voloshinov afirmaría: «la memoria histórica de la humanidad está repleta de signos ideológicos muertos incapaces de ser arena de confrontación de acentos sociales vivientes» ${ }^{82}$, puntualizando como «la clase dominante busca adjudicar al signo ideológico un carácter eterno por encima de las clases sociales, pretenda pagar y reducir al interior la lucha de valoraciones sociales que se verifica en él, tratando de convertirlo en un signo monoacentual» ${ }^{83}$. Esto, llevado al campo de las prácticas monumentales post-exhumación; explicita el desinterés de ciertas instituciones en desarrollar este tipo de prácticas, tal y como queda reflejado en la ausencia de protocolos al respecto en la Ley de Memoria Histórica de 2007 y en la propuesta de Ley de Memoria Democrática de $2020^{84}$, favoreciendo exhumaciones que no incluyan un «gesto significativo» a través de la sepultura de los cuerpos. Por ello, volviendo a Ricoeur, es importante tomar su noción de cómo ese «deber de la memoria» no queda limitado a la salvaguarda de la huella material, «sino que cultiva el sentimiento de estar obligados respecto a estos otros [...] que ya no están pero que estuvieron. Pagar la deuda, diremos, pero también someter la herencia a inventario ${ }^{85}$. De esta manera cobraría sentido la noción de que una práctica monumental desarrollada tras una exhumación estaría atendiendo en un primer momento a una necesidad praǵmática, la de reinhumar los cuerpos exhumados, pero en el momento en el que se diseña un artefacto en tanto que monumento para alojar los cuerpos se produciría un cambio sustancial. Se estaría realizando una escritura de la historia en el territorio basada en una lógica comunitaria tradicional que sobrevive pese al avance del saber biomédico de los expertos con relación al cuerpo.

\footnotetext{
${ }^{80}$ Junta de Andalucía, 2018.

${ }^{81}$ Montoto Ugarte, 2019.

82 Voloshinov, 2014, p. 47.

${ }^{83}$ Voloshinov, 2014, p. 48.

${ }^{84}$ Ministerio de la Presidencia, Relaciones con las Cortes y Memoria Democrática, 2020.

${ }^{85}$ Ricoeur, 2010, p. 121.
} 


\section{Conclusiones}

Dejando a un lado la visión popularizada por los medios, y a través del trabajo empírico del contacto con el territorio mismo donde las exhumaciones están teniendo lugar, la importancia del destino final de los cuerpos es evidente. El paradigma individualista que subyace en el fondo político del movimiento por la memoria que parte de la línea inaugurada por los sucesos de Priaranza del Bierzo del año 2000 y que conectan con esa necesidad del PSOE de revisar su programa bajo presupuestos neoliberales, pero con una imagen de «izquierda», se desmorona ante la práctica monumental post-exhumación.

Pese a que el «giro forense» haya venido de la mano de una «identity in high modernity» basada en el «yo» bajo las teorías de Anthony Giddens, Ulrich Beck y Elisabeth Beck-Gernsheim, queda explicitada la necesidad de crear referentes en el territorio, a la vez que se hace frente de manera colectiva a las limitaciones de las exhumaciones. Se ha expuesto como en los años setenta el fin de las exhumaciones no era la exhumación misma, sino la reinhumación de los cuerpos recuperados de la fosa común al interior de grandes panteones colectivos, que los dotaban de un lugar acorde a los patrones de sepultura tradicionales, y que además significaba socialmente el asesinato de aquellas personas y su agencia política en vida. Estos lugares, resultantes del trabajo de familiares y anónimos con diferentes grados de militancia, se han convertido desde entonces en puntos de referencia en la geografía histórica de las localidades donde se ubican. Resulta habitual que sean lugares de homenajes anuales por parte de organizaciones políticas y colectivos, más allá de la simple reproducción del duelo familiar. En aquel momento no fue posible la intervención de técnicos y especialistas forenses dado que el Estado no se involucró en el proceso, que quedó en manos de las comunidades locales que eventualmente recibieron apoyo municipal. La situación cambió hacia el año 2000 cuando comenzó ese nuevo periodo de exhumaciones en el que, aunque de manera irregular, han participado forenses, antropólogos físicos y arqueólogos que han aportado una metodología científica al proceso. Sin embargoo, estas intervenciones, más allá de su cuestionamiento por no tener implicaciones legales en tanto que investigación desde una fiscalía de crímenes de guerra y de Estado, tienen una problemática añadida: la mayor parte de los cuerpos exhumados no pueden ser identificados o no van a ser reclamados, de manera que, a la contra de las expectativas generadas por los medios de comunicación, los familiares, asociaciones promotoras e instituciones se han encontrado con la problemática de que tras abrir la fosa necesitan dar un destino final a los cuerpos recuperados. Así, asociaciones promotoras, familiares y ayuntamientos comenzaron a construir panteones colectivos, volviendo, por tanto, al mismo formato que se utilizó en las exhumaciones autogestionadas de los años setenta para reinhumar los cuerpos. Progresivamente, dado que se trata de una problemática 
recurrente, las autoridades autonómicas y municipales han asumido esa labor de construcción de recintos monumentales para la sepultura de los cuerpos exhumados y no identificados. No obstante, los marcos legales de 2007 y el proyectado en 2020 siguen sin atender a una necesidad que ha llevado a que muchos de los cuerpos exhumados se estén perdiendo, sean arrojados a osarios o queden almacenados en laboratorios.

Ante esta situación se propone una comprensión del proceso, que emana de un trabajo de investigación más amplio en el que se han documentado las prácticas monumentales realizadas en relación a más de 600 fosas comunes, en diferentes puntos del territorio, un trabajo que ha sido acompañado de una intensa labor de documentación cualitativa por medio de técnicas etnográficas y del cual en este texto solo se muestra una pequeña parte. Gracias a ello se ha percibido la voluntad en las prácticas monumentales realizadas tras las exhumaciones de fijar los cuerpos al territorio, de evitar su pérdida y de significarlos. Por ello, la fosa común exhumada, pese a que no atienda al criterio individualista de recuperación de los cuerpos por parte de los familiares, interpela a la sociedad de los vivos llamando a un «deber hacer» que conecta a los muertos con la acción actual por parte de los vivos al ser nosotros quienes les damos un lugar de importancia a ellos en el territorio y ellos los que nos dotan de unos referentes para el accionar presente. En consecuencia, las prácticas monumentales que tienen lugar tras las exhumaciones son entendidas como «gesto de sepultura» en los términos definidos por Paul Ricoeur, de forma que a través de ellos se hace frente a una «escritura de la historia» tal y como plantea Michel de Certeau; no obstante, en este contexto a través de medios no textuales, pero que indudablemente producen un «signo» que se ve convertido en un campo en disputa. El estudio de este tipo de prácticas resulta fundamental para el futuro, pues en un momento en el que en territorios tales como el País Vasco o Burgos, donde la mayor parte de las fosas localizadas ya han sido exhumadas, son los resultados materiales de esas prácticas monumentales los que han quedado tras la exhumación, el patrimonio a través del cual podemos relacionarnos con el pasado.

En este sentido, es urgente direccionar las investigaciones futuras en torno a los procesos de producción de memoria basados en las comunidades, dejando a un lado la exhumación en sí como proceso mitificado que represente un fin en sí mismo. Al proceso de exhumación le suceden prácticas monumentales desarrolladas por comunidades e instituciones al integrar los cuerpos exhumados en estructuras específicas con un sentido. Y es precisamente el hecho de que esas prácticas doten de un sentido a los cuerpos el que lleva a que, en tanto que signos, estén en disputa, una disputa por el sentido del pasado. Disputa en la cual las exhumaciones pueden por tanto jugar un papel clave en reforzar la producción de una escritura de la historia, o, por el contrario, derivar en la desaparición de sus rastros en el territorio. De esta manera el reto para las exhumaciones de las fosas 
comunes en el futuro, junto a la problemática de su carácter legal, subyacerá en que se aleje del recurso de lo simbólico, o, por el contrario, como planteaba Le Breton, potencie sus efectos ${ }^{86}$.

\section{Bibliografía}

Aguilar, Paloma, «Memoria y transición en España. Exhumaciones de fusilados republicanos y homenajes en su honor», Historia y Política, 39, 2018, pp. 291-325. doi: https://doi.org/10.18042/hp.39.11.

Aguilar, Paloma, y Francisco Ferrándiz, «Memory, media and spectacle: Interviú’s portrayal of Civil War exhumations in the early years of Spanish democracy», Journal of Spanish Cultural Studies 17, 1, 2016, pp. 1-25. doi: https://doi.org/10.1080/ 14636204.2015.1135599.

Aguilar Fernández, Paloma, y Leigh A. Payne, El resurgir del pasado en España: fosas de víctimas y confesiones de verdugos, Barcelona, Taurus, 2018.

Aguirre González, Jesús Vicente, Aquí nunca pasó nada: La Rioja 1936, Logroño, Ochoa, 2012.

Alonso, Antonio et al., Las exhumaciones de la Guerra Civil y la dictadura franquista 2000-2019. Estado actual y recomendaciones de futuro, Madrid, Ministerio de la Presidencia, Relaciones con las Cortes y Memoria Democrática, 2020.

Alonso Carballés, Jesús (ed.), Memorias de piedra y acero: los monumentos a las víctimas de la Guerra civil y del franquismo en Euskadi (1936-2017), GernikaLumo, Fundación Museo de la Paz de Gernika, 2017.

Anstett, Élisabeth, y Jean-Marc Dreyfus, «Introduction: why exhume? Why identify?», en Élisabeth Anstett y Jean-Mare Dreyfus (eds.), Human Remains and Identification. Mass Violence, Genocide, and the 'Forensic Turn', Manchester University Press, 2015, pp. 1-13.

Asociación para la Recuperación de la Memoria Histórica, «Los trece de Priaranza», 10 de agosto de 2000, https://memoriahistorica.org.es/los-trece-de-priaranza/ [consultado el 03/03/2021].

Barthes, Roland, Mythologies, París, Éditions Points, 2014.

Bauman, Zyǵmunt, Liquid Modernity, Cambridge, Polity Press, 2018.

Beck, Ulrich, y Elisabeth Beck-Gernsheim, Individualisation: Institutionalised Individualism and Its Social and Political Consequences, London, SAGE, 2001.

Bernecker, Walther L., y Sören Brinkmann, Kampf der Erinnerungen der Spanische Bürgerkrieg in Politik und Gesellschaft: 1936-2010, Heidelberg, Verlag Graswurzelrevolution, 2020.

Bod, Rens, «Who's Afraid of Patterns?: The Particular versus the Universal and the Meaning of Humanities 3.0», BMGN - Low Countries Historical Review 128, 4, 2013, pp. 171-180. doi: https://doi.org/10.18352/bmgn-lchr.9351.

${ }^{86}$ Le Breton, 2012, p. 184. 
Daniel Palacios González

COMEBE, «Qui som?», Espais de la Batalla de l'Ebre (web), http://www.batallaebre.org/ app/index.php?page =comebe [consultado el 03/03/2021].

De Kerangat, Zoé, «Remover cielo y tierra. Las exhumaciones de víctimas del Franquismo como fisuras del silencio en la transición», tesis doctoral, Universidad Autónoma de Madrid, 2019.

elDiario.es, «Las pruebas de ADN descartan que los restos exhumados en Guadalajara sean de Timoteo Mendieta», 30 de diciembre de 2016, https://www.eldiario.es/ clm/Pruebas-ADN-descartan-Timoteo-Mendieta_0_596340668.html [consultado el 03/03/2021].

EITB, «Inhumados en Pamplona los restos de 46 víctimas del golpe militar de 1936», 1 de abril de 2019, https:/www.eitb.eus/es/noticias/politica/detalle/6307643/ inhumadas-pamplona-46-victimas-golpe-militar-1936-1-abril-2019/ [consultado el 03/03/2021].

Etxeberria Gabilondo, Francisco et al., «Antropología del pasado reciente: una fosa común de la Guerra Civil Española en Priaranza del Bierzo (León)», Antropología y biodiversidad, 1, 2002, pp. 431-446.

Etxeberria Gabilondo, Francisco, y Queralt Solé i Barjau, «Fosas comunes de la Guerra Civil en el siglo XXI: antecedentes, interdisciplinariedad y legislación», Historia contemporánea, 60, 2019, pp. 401-438.

Fernández, Andrés, «Los trabajos en las fosas comunes del cementerio de San Rafael (Málaga). Metodología arqueológica y fuentes documentales», Arch-e, Revista andaluza de archivo, 5, 2010, pp. 177-203.

Ferrándiz, Francisco, «The Return of Civil War Ghosts: The Ethnography of Exhumations in Contemporary Spain», Anthropology Today, 22, 3, 2006, pp. 7-12. doi: https://doi.org/10.1111/j.1467-8322.2006.00437.x

Ferrándiz, Francisco, «Gritos y susurros: Exhumaciones y relatos de la derrota en la España del siǵlo XXI», en Ángel Martínez Hernández, Lina Masana y Susan M. DiGiacomo (eds.), Evidencias y narrativas en la atención sanitaria: Una perspectiva antropológica, Tarragona, Publicaciones URV, 2013, pp. 447-478.

Ferrándiz, Francisco, El pasado bajo tierra, Barcelona, Anthropos, 2014.

Ferrándiz, Francisco, «Death on the Move», en Antonius Robben (ed.), A Companion to the Anthropology of Death, Hoboken, John Wiley \& Sons, 2018, pp. 189-204. doi: https://doi.org/10.1002/9781119222422.ch14.

Fouce Fernández, José Guillermo, «La Memoria Histórica cierra heridas», Nómadas: Critical Journal of Social and Juridical Sciences, 20, 2008, pp. 519-521.

Fuentes, Ángeles, «Exhumació i arqueologia forense. Els afusellats a Villamayor de los Montes (Burgos)», L'Aveç, 299, 2005, pp. 28-30.

Gabarda Cebellán, Vicente A., «Un aspecte de la repressió franquista: els afusellaments a Paterna», Afers: fulls de recerca i pensament, 2, 3, 1986, pp. 261-70.

Gabarda Cebellán, Vicente A., «El Cementeri de Paterna com a exemple de monumentalització popular», en Postguerres. Congres internacional, Barcelona, Universitat de Barcelona, 2019.

Gastón Aguas, José Miguel, y César Layana Ilundain (eds.), Bajo tierra: exhumaciones en Navarra = Lur azpian: desobiratzeak Nafarroan, 1939-2019, Pamplona, Gobierno de Navarra, 2019. 
Giddens, Anthony, Modernity and Self-Identity: Self and Society in the Late Modern Age, Cambridge, Polity Press, 1991.

Giddens, Anthony, The Third Way and Its Critics, Hoboken, Wiley, 2013.

Giráldez Díaz, Javier, «Política de la memoria y memoria de la política. Una reflexión sobre la memoria histórica en Andalucía», tesis doctoral, Universidad de Sevilla, 2014.

Gogora, «Un Columbario para «honrar la memoria y dignificar el ejemplo de quienes dieron su vida en defensa de la democracia y la libertad»», 30 de enero de 2017, https://www.gogora.euskadi.eus/noticias/-/noticia/un-columbario-para-honrarla-memoria-y-dignificar-el-ejemplo-de-quienes-dieron-su-vida-en-defensa-dela-democracia-y-la-libertad/ [consultado 03/03/2021].

Hobsbawm, Eric, The Age of Extremes: A History of the World, 1914-1991, New York, Vintage Books, 1996.

Iǵlesias, Javier, «Proceso de exhumación, cadena de custodia e identificación de los cuerpos. Aspectos técnicos y jurídicos. Antropología forense durante los trabajos en el Cementerio Municipal de Paterna», I Jornades de Memòria Democràtica a Paterna, Valencia, Diputación de Valencia, 2017.

Joric, Carlos, «Las cunetas del franquismo», Historia y vida, 608, 2018, pp. 10-11.

Junta de Andalucía, «Díaz valora la memoria histórica para conocer la verdad, reparar y cerrar heridas», 13 de junio de 2018, https://www.youtube.com/ watch?v=3Y6g22xFCmk [consultado el 03/03/2021].

Le Breton, David, Antropología del cuerpo y modernidad, Buenos Aires, Nueva Visión, 2012.

Martín Chiappe, María Laura, «Micropolíticas del entierro digno: exhumaciones contemporáneas de víctimas del franquismo y culturas memoriales transnacionales en el Valle del Tiétar», tesis doctoral, Universidad Autónoma de Madrid, 2020.

Martín Maestro, Miguel Ángel, «El cine impostor. El silencio de otros (Almudena Carracedo, Roberto Bahar, 2018)», últimoCero I Noticias de Valladolid, 3 de mayo de 2019, http://ultimocero.com/opinion/2019/05/03/cine-impostor-silencio-otrosalmudena-carracedo-roberto-bahar-2018/ [consultado el 03/03/2021].

Martínez, Concha, «Caravana republicana 14 de 2019», Agenda Feminista.org (web), 4 de junio de 2019, https://agendafeminista.org/evento/caravana-republicana14-abril-2019/ [consultado el 03/03/2021].

Mbembe, Achille, Necropolitics, Durham, Duke University Press, 2019.

Ministerio de la Presidencia, Relaciones con las Cortes y Memoria Democrática, «MPR. 11/11/2020. Anteproyecto de Ley de Memoria Democrática [Servicios a la ciudadanía/Participación ciudadana/Audiencia e información]», 11 de noviembre de 2020, pp. 37-38, https://www.mpr.gob.es/servicios/participacion/audienciapublica/Paginas/VSGT2020/apl-memoria-democratica.aspx [consultado el 03/03/2021].

Mir, Conxita, y Josep Gelonch (eds.), Duelo y memoria espacios para el recuerdo de las víctimas de la represión franquista en perspectiva comparada, Lleida, Edicions de la Universitat de Lleida, 2013.

Montoto Ugarte, Marina, «Las víctimas del franquismo en 'la Querella Argentina': luchas por el reconocimiento y nuevas desigualdades», Papeles del CEIC. Inter- 
national Journal on Collective Identity Research, 1, 2017, papel 164, pp. 1-25. doi:http://dx.doi.org/10.1387/pceic.16919

Montoto Ugarte, Marina, «Un viaje de ida y vuelta: la construcción social de la «víctima» en la querella argentina contra los crímenes del franquismo», tesis doctoral, Universidad Complutense de Madrid, 2019.

Peinado, Arturo, «Anteproyecto de Ley de Memoria Democrática (I): deudas pendientes», El Estado.Net, 10 de agosto de 2020, https://elestado.net/2020/10/05/anteproyecto-ley-memoria-democratica-avances-deudas-pendientes/ [consultado el 03/03/2021].

Peinado, Arturo, «Las fosas del franquismo: qué y para qué», Cuartopoder (blog), Cuarto Poder, 11 de febrero de 2020, https://www.cuartopoder.es/ideas/2020/02/12/lasfosas-del-franquismo-arturo-peinado/ [consultado el 03/03/2021].

Ramos, Jordi, «Intervencions arqueològiques a les fosses del Front de l'Ebre. Similitudes i diferències.», en Actes de la II Jornada d'Arqueologia i Patrimoni de la Guerra Civil al Front de l'Ebre, Tortosa, 2017, pp. 61-77.

Renshaw, Layla, Exhuming Loss: Memory, Materiality and Mass Graves of the Spanish Civil War, New York, Routledge, 2016.

Renshaw, Layla, «Ethical Considerations in the Investigation and Commemoration of Mass Graves from the Spanish Civil War», en Kirsty Squires, David Errickson y Nicholas Márquez-Grant (eds.), Ethical Approaches to Human Remains: A Global Challenge in Bioarchaeology and Forensic Anthropology, Cham, Springer International Publishing, 2019, pp. 533-534. doi: https://doi.org/10.1007/978-3030-32926-6_24.

Ricoeur, Paul, La memoria, la historia, el olvido, Madrid, Trotta, 2010.

Ródenas, Queta, Primer 'cementeri civil' de la ciutat de Castelló, Castellón, Grup per la Recerca de la Memòria Històrica de Castelló, 2016.

RTVE, «Repor - Abrir fosas, cerrar heridas», RTVE.es, 2019, https://www.rtve.es/alacarta/videos/repor/repor-abrir-fosas-cerrar-heridas/5256759/ [consultado el 03/03/2021].

Ruiz, Eva, «Fosas comunes en el cementerio de San Fernando de Sevilla», Todos los nombres.org (web), https://studylib.es/doc/6222409/fosas-comunes-en-el-cementerio-de-san-fernando-de-sevilla [consultado el 03/03/2021].

Saqqa Carazo, Miriam, «Las exhumaciones de los Caídos por Dios y por España: la gestión de los cuerpos», en Juan Andrés Blanco Rodríguez, Jesús A Martínez Martín y Ángel Viñas Martín (eds.), Luces sobre un pasado deformado: la Guerra Civil ochenta años después, Madrid, Marcial Pons, Ediciones de Historia, 2020, pp. 505-526.

Schweitzer, N. J., y Michael J. Saks, «The CSI Effect: Popular Fiction About Forensic Science Affects Public Expectations About Real Forensic Science», SSRN Scholarly Paper, Rochester, Social Science Research Network, 2007.

Suárez, Alberto, «El Ayuntamiento de Castelló inicia los trámites para exhumar a siete víctimas del franquismo», Cadena SER, 22 de abril de 2019, https://cadenaser. com/emisora/2019/04/22/radio_castellon/1555924631_384430.html [consultado el 03/03/2021].

Thomas, Hughh, La guerra civil española, Barcelona, Debolsillo, 2003. 
Thompson, John, «Tres monumentos que conmemoran vítimas do franquismo: participación cidadá e a confluencia de historia oral e historiografía», Murguía: revista galega de historia, 29-30, 2014, pp. 55-70.

Voloshinov, Valentin Nikolaevich, El marxismo y la filosofía del lenguaje. Los principales problemas del método sociológico en la ciencia del lenguaje, trad. Tatiana Bubnova, Buenos Aires, Godot, 2014.

Yusta Rodrigo, Mercedes, «El pasado como trauma: Historia, memoria y «recuperación de la memoria histórica» en la España actual», Pandora: revue d'etudes hispaniques, 12, 2014, pp. 23-41.

20minutos, "Asociaciones de familiares de fusilados de Paterna se unen en una federación para acelerar las exhumaciones», www.20minutos.es (web), 6 de marzo de 2019, https://www.20minutos.es/noticia/3580920/0/asociaciones-familiaresfusilados-paterna-se-unen-federacion-para-acelerar-exhumaciones/ [consultado el 03/03/2021]. 
